\title{
Emerging Profiles of Female Marketing Managers in the Islamic Republic of Iran: Winning and Losing Competitive Laps in a Relay Race against Male Counterparts
}

\author{
Farrokh Safavi ${ }^{1,2}$ \\ ${ }^{1}$ Western Washington University, Bellingham, Washington, USA \\ ${ }^{2}$ Tehran University, Tehran, Iran \\ Correspondence: Farrokh Safavi, Western Washington University, Bellingham, Washington, USA. E-mail: \\ Farrokh.Safavi@wwu.edu
}

Received: February 28, 2013

Accepted: March 27, 2013 Online Published: April 15, 2013

doi:10.5539/ijms.v5n3p73

URL: http://dx.doi.org/10.5539/ijms.v5n3p73

\begin{abstract}
In Western economies the theories and paradigms of marketing management are developed on the basis of prevailing resources and environments with little, if any, consideration of the personal characteristics of the implementers. In many non-Western cultures, however, personalities of the implementers affect the design and execution of marketing strategies and tactics. This paper views the emerging roles of the young and inspiring female executives in shaping the marketing practices of the state-owned and private enterprises in the Islamic Republic of Iran. It examines the deep-rooted constraints that the female marketing managers have been subjected to at various stages of their employment process, including preparation, employment access, retention, and promotion to the position of marketing executives in organizations which have been traditionally governed by men. As the women have recently succeeded in occupying more university seats than their counterparts, a race has begun to capture key positions in the marketing organizations and break the glass ceiling in competition with their male counterparts. Using the metaphor of a relay race, the author has studied the performance of the Iranian women at each lap under the prevailing constraints and opportunities. A longitudinal study of Iranian women entering Tehran University during the period of 1999-2012, encompassing admission data, scientific preparation, job application, organizational culture, and external communications has been made in a series of field research. A model is developed to portray success and failure of the women at each lap (stage) of their marketing management functions.
\end{abstract}

Keywords: Iranian marketing managers, women marketing managers, gender-based competition for university admission

\section{Introduction}

\subsection{Divergent Behavior in a Global Setting}

In Western economies the theories and concepts of marketing management deal with adapting to the continuously evolving environment. The emotional side of the marketer is expected to be contained and excluded from the decision-making process. In a number of non-western cultures, including Iran, the personalities of marketing managers affect the choice of strategies. This can be influenced bycultural norms of the society, the absence of adequate information, and limited access to required resources. Accordingly, marketing concepts, theories, and strategies cannot be fully developed without the consideration of the individuals who implement them.

This paper examines a host of environmental factors that shape the mindset of the Iranian women as they undertake managerial responsibilities for marketing functions. The backbone of these environments are cultural and social norms, supported by laws and politics, challenged by the new waves from social media, and entangled in a bureaucracy which stifles genuine efforts for change. Without identifying these factors and their dynamics, it would be difficult to understand the risk aversion orientation which many female marketing managers have developed. Conformity with the organizational structure and culture has been deemed to be safe conduct. Those women who have challenged the validity or fairness of organizational norms have often encountered frustration and dismay. In some instances, however, the young women who were interviewed by the present author 
acknowledged the helpful assistance they received from a number of officials in finding solutions to their dilemma. Pursuant to a growing public assistance by the Islamic Republic, the Iranian Parliament recently increased the legal period for maternity leave to nine months, with two weeks of required leave for the husband as well (Official Gazette, 2013).

Initial studies for this paper were conducted in the period 1999-2009 and the findings were presented in a national conference in 2009 (Safavi, 2009). New developments that emerged during the period 2010-2012 were examined in a recent presentation (Safavi, 2012). This paper integrates the findings of both studies and incorporates the valuable comments received by reviewers that enhanced the scope of its contents. It aims at providing a holistic view of the female landscape in business and the market place of the Islamic Republic of Iran under the conditions of trade sanctions and suppressed isolation.

\subsection{The Emerging Environment}

Tehran University is an appropriate place for observing the behavior of Iranian women as they compete with young men in securing a seat and performing well in rigorous competitive admission tests. Established in 1934, Tehran University has retained its status as the oldest and most prestigious public university in the country, and supplied highly educated and skilled individuals for Iranian industries, including the flourishing business communities. As observed by Beck and Nashat (2004), most studies about Iranian women focus on a small group of Persian descent, in the middle and upper income classes. This paper does not suffer from the small group focus. Tehran University admits nearly $90 \%$ of its students from the provinces and rural communities across the nation. Therefore, challenges exhibited by the students and graduates of Tehran University reflect a cross-national behavior of the young Iranians.

Marketing managers receive their education at the School of Management, which constitutes one of the twenty-four principal faculties of Tehran University. With more than fifty-nine years of experience in training managers for Iran and Middle East regions (established in 1954) the school has been a major breeding ground for business professionals and corporate executives. Entrance to the Management School is through an extremely competitive examination with roughly one out of 100 applicants admitted each year. Until recently, most entrants have been young ambitious men, envisioning leading positions in the expanding Iranian business environment. In the 2004-05 academic year, the number of women exceeded the number of men for the first time and they continued to hold on to their lead until 2012.

Table 1 presents the number of male and female students at Tehran University and its School of Management during the 1999-2012 academic years. The bar charts in Figure 1 exhibit the rapid increase of women throughout the first decade of the $21^{\text {st }}$ century. At the end of $20^{\text {th }}$ century (academic year 1998-1999) there were only 9,583 female students versus 16,530 male students, almost double the number of female students. The table shows that in the first decade of the $21^{\text {st }}$ century the population of female students rose to 15,169 while the number of male students declined to 14,527 . The data depicts the prevalence of a very challenging education environment for young Iranian women. Their success was not achieved without posing a strong challenge to their male counterparts. Roughly one percent of the Iranian students who take the notoriously demanding entrance examination for public universities are admitted at Tehran University.

Table 1 and Figure 1 further exhibit a peculiar landscape of the student body in the first three years of the second decade of the $21^{\text {st }}$ century. While the number of female students increased from 15,169 in 2009 to 16,554 in 2010 (a leap of $9.13 \%$ ), the number of male students experienced a larger increase of $11.03 \%$, representing an unprecedented growthfrom 14,527 male students in 2009, to 16,129 in 2010. This was due to the fact that since 2006 the Iranian government had adopted a strategy of gender equalization in admitting students to public universities (Fararou, 2008). Accordingly, the Assessment Organization of the Ministry of Science,Research, and Technology had placed a quota for male and female students, which affected 26 disciplines in 2006 and 39 disciplines in 2007(Amouzesh, 2008). According to these quotas, at least $40 \%$ of enrollment was reserved for both males and females, while the remaining $20 \%$ of available seats were open to competitive endeavors. The controlled number of male and female students who entered Tehran University in the 2006-2007 academic year caused the number of male and female students in the academic year 2007-2008 to equalize both in the university (14,926 male, 14,943 female students) and in the School of Management (1,042 male, 1,132 female students). The continuation of an arbitrary quota caused a gradual increase of male over female students in the 2011-2012 academic year at Tehran University (16,546 male versus 16,396 female students) and in the School of Management (1,153 male versus 1,135 female students). The government had initiated the quota in response to the needs of social organizations for educated human resources, where many young women were apparently not willing to serve, which was not ill motivated. However, as reported by Ezzati (2008) and Ranjipour (2008), 
many Iranian women felt they were discriminated against but had to cope with the externally imposed restrictions, while maintaining hope for opportunities in the near future.

Table 1. Enrollment of active students in the school of management and Tehran University, by gender, and proportion of difference between number of male and female students in relation to the total number of students during the academic years 1998-99 and 2011-12

\begin{tabular}{|c|c|c|c|c|c|c|c|c|c|c|c|c|c|c|}
\hline & 1999 & 2000 & 2001 & 2002 & 2003 & 2004 & 2005 & 2006 & 2007 & 2008 & 2009 & 2010 & 2011 & 2012 \\
\hline Mgt Male & 1144 & 1214 & 1188 & 1018 & 993 & 990 & 786 & 821 & 803 & 1042 & 868 & 1304 & 1120 & 1153 \\
\hline Mgt Female & 345 & 528 & 654 & 676 & 839 & 991 & 828 & 911 & 980 & 1132 & 1167 & 1453 & 1196 & 1135 \\
\hline Mgt Diff & 799 & 686 & 534 & 342 & 154 & -1 & -42 & -90 & -177 & -90 & -299 & -149 & -76 & 18 \\
\hline Mgt Total & 1489 & 1742 & 1842 & 1694 & 1832 & 1981 & 1614 & 1732 & 1783 & 2174 & 2035 & 2757 & 2316 & 2288 \\
\hline \multicolumn{15}{|l|}{ Mgt [(M-F)/ } \\
\hline Total] & 0.54 & 0.39 & 0.29 & 0.20 & 0.08 & 0.00 & -0.03 & -0.05 & -0.10 & -0.04 & -0.15 & -0.05 & -0.03 & 0.01 \\
\hline Univ Male & 16530 & 15779 & 14852 & 14053 & 13394 & 13136 & 13073 & 13364 & 13379 & 14926 & 14527 & 16129 & 16110 & 16546 \\
\hline Univ Female & 9583 & 10856 & 11681 & 11865 & 12394 & 13206 & 13319 & 13890 & 13926 & 14943 & 15169 & 16554 & 16663 & 16396 \\
\hline Univ Diff & 6947 & 4923 & 3171 & 2188 & 1000 & -70 & -246 & -526 & -547 & -17 & -642 & -425 & -553 & 150 \\
\hline Univ Total & 26113 & 26635 & 26533 & 25918 & 25788 & 26342 & 26392 & 27254 & 27305 & 29869 & 29696 & 32683 & 32773 & 33142 \\
\hline \multicolumn{15}{|l|}{ Univ [(M-F)/ } \\
\hline Total] & 0.27 & 0.18 & 0.12 & 0.08 & 0.04 & 0.00 & -0.01 & -0.02 & -0.02 & 0.00 & -0.02 & -0.01 & -0.02 & 0.00 \\
\hline
\end{tabular}

Source: Data courtesy of the Information Technology Division of Tehran University, January 2012

\subsubsection{Frustrations and Agony beyond Campus Experience: Challenges in Recruitment and Job Promotion}

Denial of access to university education according to the gender quota system, while successfully passing the rigorous entrance examination, has not been the only source of frustration for Iranian women. Movement within the campus where specific places are designated for women gatherings has further been an additional source of inconvenience. Upon graduation, an array of societal impediments and bureaucratic gridlocks negates their efforts. The prevalence of an organizational culture views managerial positions as fundamentally a male privilege. Specifically, daily networking with traders in the traditional markets (bazaar) deter female access to lucrative marketing positions. Keshavarzian (2009) examines the historically cemented relationship between the Iranian clerics and traditional merchants (75azaar) and concludes that the behavioral outcome of this alliance has restricted women's participation in traditional markets. Parental pressure discourages unmarried women to seek employment that involves extensive contact with men, despite the career importance. For married women, the discouragement stems from the husband. Many managerial positions require extensive working hours. There are real and perceived risks associated with being outside the home, even in the early evening. The society usually frowns upon this practice. In short, there is a highly restrictive environment for recruitment and personal enhancement of young women in the marketing domain. As the research for this project reveals, it has been a growing challenge to break the glass ceiling in the organizations and move upward in the male dominated economy.

\subsection{The Research Objectives}

This paper explores the challenges that Iranian women put forth in preparing for careers in marketing and marketing management, and competing for success in a male dominated society. The entire process of securing and holding a marketing management career is segmented in five phases: seeking university education, performing well in their studies, seeking rewarding careers, advancing to executive positions, and rebuilding the environment for career advancement. It is assumed that by observing and analyzing women's challenges at each phase, and exploring dynamic relationship among them, the sources of frustrations would be recognized and prevented. The paper further attempts to explain how the theories and strategies of marketing management are affected by the learning experience of the young and educated Iranian woman in the Islamic Republic. 


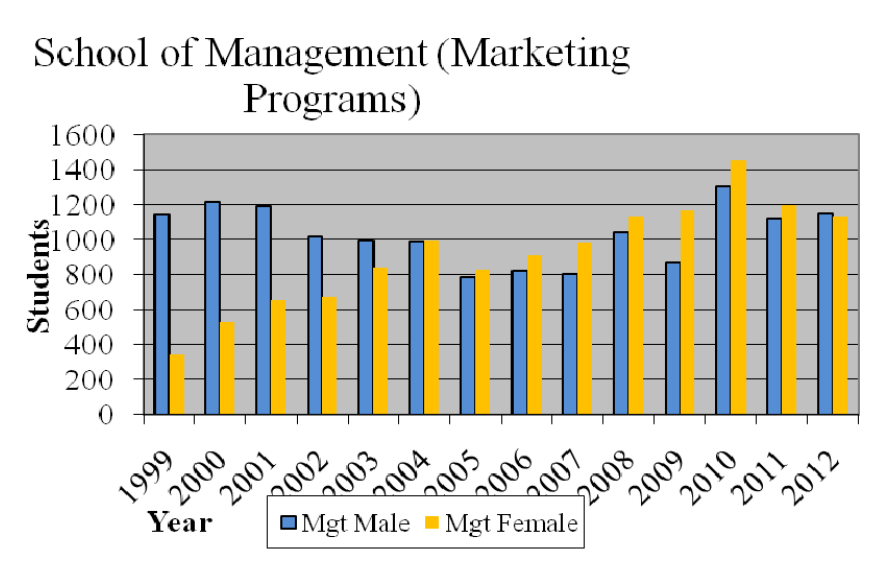

Tehran University

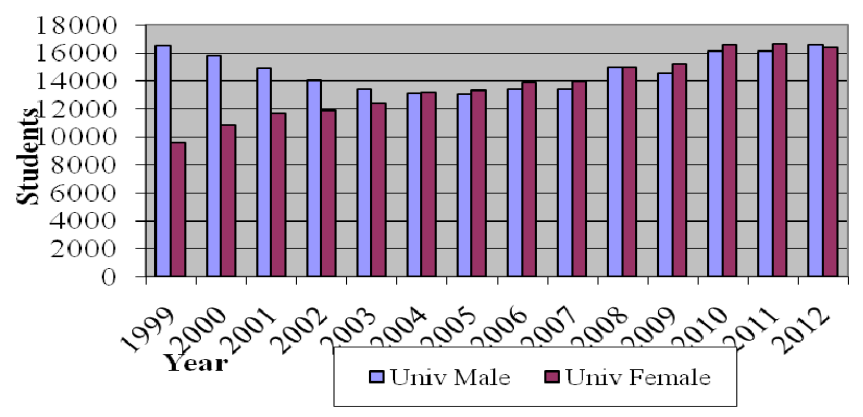

Figure 1. Number of male and female students in Tehran University and its school of management between the academic years ending 1999 and 2012

\section{Methodology}

\subsection{The Research Method}

The period for this study covers the last year of the $20^{\text {th }}$ century and the first thirteen years of the $21^{\text {st }}$ century. During this period the author made at least two yearly trips to Iran where he taught at Tehran University as a visiting professor and observed the behavior of Ph.D. and MBA students at the school, in the job market, and throughout organizations where they were employed. These opportunities involved lecturing six MBA and five Ph.D. classes, offering seminars at three summer sessions to masters and doctoral students, and many one day workshops for graduate students of other universities. More than forty-six state-owned and private organizations were visited and a sixty-four of their executives and managers were interviewed. In the majority of visits discussions were carried informally and no on-sight recording of conversation was made (Note 1). Twenty-two women managers were interviewed outside their organizations, also in informal mode. Discussions were made with people in three centers for women studies, and four editors of women journals. In total, 135 individuals who were associated in one way or other with the tasks of social and economic development of the Iranian women were interviewed, either individually or through focus group.

Direct observation of the behavior of male and female management students was made through class interaction and external communications. Efforts were made to explore factors that contributed to the young women's superior performance in passing highly competitive entrance exams, performing well at college, obtaining desirable careers, and advancing within an organizational hierarchy to managerial positions. Enrollment statistics for various institutions of Tehran University, unpublished and hard to obtain, were meticulously collected from the information division of Tehran University and processed for quantitative analysis. A thorough review of literature in English and Farsi was made to incorporate similar research with the findings of this project. 


\subsection{A Review of the Literature}

Many observers of the conditions of women in Iran have been critical of the treatment they receive from their families, society, and the government. In a clinical study of couple equality in Iran, Moghadam et al (2009) observed the gender inequality largely reported by women. Hoodfar and Sadr (2010) maintain that the lack of constructive mechanisms in the present structure of the state has stifled demands for gender equality to be translated into legal change. From their study of women's involvement in internal politics in Iran, Kar and Farshi (2008) conclude that while most women believe there would be no improvement in their situation, there are still a group of religious scholars and jurists who believe that an appropriate interpretation of Islam would remove discrimination against women. Keshavarz (2008) addresses some of the problems with viewing the restrictions imposed on the Iranian women from the viewpoint of the women sympathizers around the world, reflecting a pro-woman orientation to the situation of the Iranian women. From their long essay on participation of the Iranian women in the academic world, Khosrokhavar and Ghaneirad (2010) attribute their lower-level advancement to the "patriarchal mindset of the Iranian power-holders." Mehran (2009) suggests that by "undoing gender" the Iranian women would be able to reach higher positions in academics. Jahanshahrad (2012) has concluded from her research on the interrelation between democratization and the women's movement in Iran that in the absence of a proper political party system, the prevalence of the women's press has provided a venue to debate women issues in the Islamic Republic. Tahmasebi-Birgani (2010) explains how the Iranian women's movements have been historically nonviolent as opposed to those advocated by the students and workers.

In contrast to the sharp criticism of secular scholars and political strategists, there are few observers who see no deficiencies in the Islamic laws to promote women's rights. They have made government orientations responsible for the gender inequality and injustice (Maftei, 2010). Terman (2010) recognizes the challenge of revolutionary Muslim women in the social and political development of Iran, but concludes that the authorities, who merely display public support for the government projects, have compromised their efforts. Sakurai (2012) noted that although the Islamic Republic has established an institute for the women of Shi'ite Islam to become educators and publicists, the authorities nonetheless do not allow its graduates to issue a competent legal opinion on the basis of the Islamic law (shari a). In their studies of women empowerment in the city of Shiraz,Nikkhah et al (2012) observed a moderate level of self-esteem and gender awareness, which provides a mild level of empowerment.

There are also a group of observers and commentators who see biases in the studies of women's issues in Iran. They warn against lopsided approaches to women studies and call for objectivity and fairness in examination of gender equality. Osanloo (2009) warns against hasty and superficial judgment on the binary of religious and secular orientations toward Iranian women. Afshari (2012) contradicts Osanloo's approach, and claims that it fails to provide meaningful guidelines for the study of human rights in Iran. Bahramitash and Kazemipour(2006) challenge the 'Westerners' stereotypical views on women in Iran and assert that the Islamic doctrine has little impact on the evolution of Iranian women to social positions while unmarried, marry at a higher age, and self-reliant on choosing a husband.

\subsection{Discussion}

Figure 2 presents a flowchart depicting the challenges of young Iranian women at the five consecutive phases of a process that involves securing an employment position in a female-restricted environment. The five phases include: passing through a highly competitive university admission test, receiving a relevant education at an accredited university, scouring the job market for a desirable career, advancing within the organization, and changing the restrictive environment into opportunities for advancement. Employment not only has helped the Iranian women gain economic security, provided them a healthier life than the housewives. In a survey of 110 employed and 110 housewives selected randomly from ten healthcare centers in the city of Zahedan, Iran, Kerman Saravi et al (2012) concluded that the employed women enjoyed better health as an indicator of the quality of life than the housewives.

In phase 1 only a single factor dominates. It involves passing the competitive admission tests to public universities and preparing for the marketing profession. In phases 2 through 4, six major factors are observed. They are grouped into three categories of A) marketing-specific factors, shown in rectangles; B) organization-specific factors, depicted in an oval shape; and C) environment-specific factors, exhibited in anangle shape. Within each category, two dominant factors are selected to highlight the type of challenges that women executives confront in their struggle to obtain successful careers. A feedback mechanism from phase 5 would enrich the performance outlay in phase 1 . 


\subsubsection{Phase 1: The Challenge of Competing with Men on the University Admission Tests}

The first and foremost requirement for securing a marketing management position is to have a university degree, preferably in marketing or related fields. Over the past fifteen years more than one million pre-university graduates have taken the university admission tests each year, with admission of $30 \%$ or less. Women continuously outperform their male counterparts and occupy more seats. By the middle of the first decade of the $21^{\text {st }}$ century an admission ratio of 3 to 2 in favor of female students changed the campus to a female landscape and brought hope for female success in professional careers.(Fararou, 2008)

Government's gender-equalization strategies of 2006 and 2007 brought to a halt an influx of qualified applicants to public universities in twenty-six and thirty-nine disciplines, respectively. They prevented the rapid growth of women admission. Many Iranian women interpreted the new strategies as an injustice to their struggle for achieving competitive performance with men.

Phase 1 Conclusion: Success of female students in accessing university education has been the result of the long years of efforts and agony in receiving pre-university education. As Rezaee et al (2012) noted, the gender parity index (GPI) in elementary education was increased from 0.90 in the school year of 1990-91 to 0.96 in 1999-2000, reflecting more girls' attendance in primary schools. In the same period the GPI for the high school education increased from 0.73 to a solid 0.92 , reflecting a surge in young female desires for the secondary education.

\subsubsection{Phase 2: The Challenge of Learning in a Woman-Restrictive Environment}

The following phenomena were observed through teaching six MBA and five Ph.D. classes at Tehran University, in addition to three joint MBA and Ph.D. summer sessions, and seven management development programs.

\subsubsection{The Challenge of Seeking a Well-Rounded Marketing Education}

From among 60+ marketing functions that are practiced today worldwide, the Iranian universities offer no more than fifteen functions. Tehran University covers twelve areas in its undergraduate and graduate programs. Due to time constraints, coverage is not broad enough to provide a holistic view of the entire marketing functions and the executive abilities to manage them. Although this particular constraint is also experienced by the male students, its prevalence has posed a serious challenge to the Iranian women in seeking a specialized marketing education.

\subsubsection{The Challenge of Removing the Thesis Requirement}

Tehran University is among a few academic institutions that require MBA students to write a thesis. The process involves a structured, lengthy procedure that requires at least one semester of full time research. It is doubtful the outcome of the research work would enable the graduates to be better marketers. This has been partly due to frustrations with obtaining corporate data for research work, even from state-owned enterprises. Many MBA students, and particularly the women who encounter more resistance from the authorities in obtaining research data, have petitioned for elimination of the thesis requirement. No positive response has been given, however. Once again this challenge is shared by both men and women.

\subsubsection{The Challenge of Overcoming an Imposed Gender Space}

Library reading rooms, dining areas, coffee shops, and prayer rooms in Iranian universities are segregated by gender. Even though classrooms are coeducational, the imposed culture of gender segregation has forced the female students to associate with their own cliques and forego the opportunity of healthy academic encounters with their male classmates. A notable outgrowth of this gender segregation has been the unfamiliarity of women graduates with the gender specific attributes of men at work. When the female management graduates enter the job market, they are not fully prepared to effectively interact with men, let alone lead them in managerial positions.

\subsubsection{The Challenge of Institutionalizing Summer Programs to Earn Academic Credits}

Summer employment is as not pervasive for Iranian students as it is in Western economies. As the opportunities for recreation and entertainment are still very limited for female students, summer time usually reflects boredom. Public universities do not offer summer sessions, at least for credit, and thereby suppress opportunities for continuous learning and earlier entrance into the job market. Many students and faculty, including the present author, have petitioned for summer education but did not receive positive actions. Consequently, a significant portion of students' learning period, i.e. three summer sessions, which would be equivalent to one academic year, is wasted in an economy that desperately needs educated professionals for economic growth. 


\subsubsection{The Challenge of Seeking Marketing Knowledge beyond the Classroom Walls}

Limited opportunities exist for quality internship programs in marketing other than those which promote products and generate revenues for corporations. Usually no academic credit is awarded. Female students have demonstrated more eagerness than male students but were confronted with resistance from business organizations. As the law requires women to maintain their Islamic dress code at work, and the responsibility for observing the law rests on the organizations, many executives are reluctant to take the risk of confrontation with the authorities. Male interns are deemed to be less risky in maintaining a working environment in accordance to the Iranian laws than women. This has led to favoritism towards men at the cost of reducing practical learning opportunities for women.

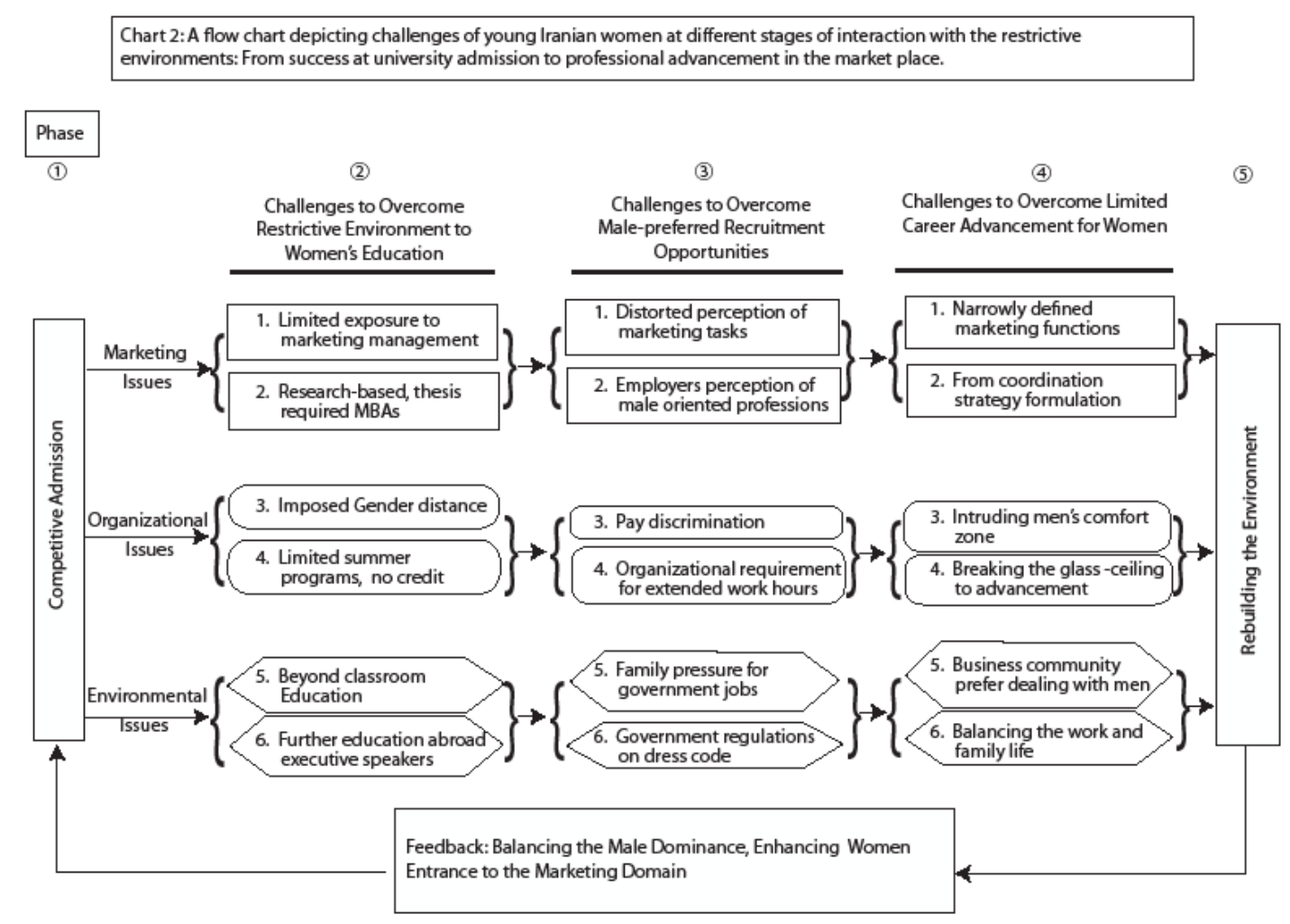

Figure 2. Diagram depicting challenges facing Iranian women in academic preparation, employment access, and promotion to the position of marketing executives in the Islamic Republic of Iran

\subsubsection{The Challenge of Seeking Further Education Abroad}

Ph.D. programs at the School of Management have limited enrolment opportunities. Every year more than 800 $\mathrm{Ph} . D$. applicants take the competitive entrance exams, but less than 80 are admitted, no more than six in marketing. Another 40 students are admitted for a fee that is very high by national standards. Such an overly restrictive environment has caused many MBA students to apply to foreign universities for their doctorates. Not surprisingly, the young women demonstrated greater enthusiasm and devotion to pursue their education than young men. However, two factors have stifled their efforts. One has been the high cost of education abroad due to diminishing value of local currency (partly due to trade sanctions). The second factor pertains to the parents' reluctance to pay for the high cost of their daughters' education in North American and West European countries. Sons have traditionally been favored over daughters for studying abroad. Parental discrimination is fading away, however.

Phase 2 Conclusion: While female students successfully overcome the challenge of being admitted to public universities, they do not find the educational environment conducive to their learning process. Many of them are 
not adequately prepared to confront the challenge of seeking rewarding employment in the business community, particularly when cultural biases in favor of men prevails.

\subsubsection{Phase 3: The Challenge of Seeking Employment in a Male-Dominated Profession}

Information with respect to this phase of the study was collected through visits to forty-six corporations and interviewing 42 male and 22 female managers.

\subsubsection{The Challenge of Confronting Distorted Perceptions of Marketing Tasks}

Female marketers have encountered complexities in seeking employment in marketing areas on the ground that most employers perceived a narrow view of marketing and recruited marketing graduates for mostly sales tasks. It has been a great challenge to convince corporate executives that marketing begins with learning about consumer needs and developing products that satisfy them. Management maintains the traditional selling orientation and believe that anything can be sold with the right promotion and selling tactics.

\subsubsection{The Challenge of Confronting Recruiters' Perception of the Male-Oriented Professions}

Traditionally, the Iranian corporations have viewed marketing as a male-specific trade and confined their recruitment opportunities to men. This orientation has been fortified by the policies of many executives under the Islamic republic where restrictions on female attire, their communication with men, and movement outside the workplace have increased substantially. Many employers believe that recruitment of women for marketing positions would undermine the ability to market their goods and services in increasingly competitive environments. The female MBAs have to demonstrate extra aptitude to secure the job.

\subsubsection{The Challenge of Overcoming Pay Discrimination}

While government regulations advocate equal pay for equal jobs, many recruiters of young women, single or married, offer lower salaries than they grant their male employees. Their rationale focuses on the practical reality of the household family where single women traditionally live with parents without contributing much to household expenditure. With respect to compensating married women, the Islamic laws require the husband to be responsible for all basic expenditures of the wife, leaving the female employee with no urgent need for higher pay. While this ideology worked well in the past, the growing financial commitment of the present day household requires women to contribute heavily to family expenses. The incompatibility of the organizational culture with the economic realities of modern time has frustrated many Iranian women in their pursuit of rewarding professional opportunities.

\subsubsection{The Challenge of Meeting Organizational Requirements for Extended Work Hours}

The rapid pace of doing business in Iran requires managers to continue working after hours. The environment, both internal and external, is perceived to be unsafe by the parents and husbands during evening hours. When female marketers are asked to remain at work after hours, it can potentially become a source of tension between the woman and the relatives. Employers prefer recruiting male applicants for their extended working potentials. It is a great challenge for women to convince the recruiters that they can also remain on the job for extended working hours.

\subsubsection{The Challenge of Resisting Parental Pressure to Seek Protected Government Jobs}

In the current Iranian socio-economic atmosphere, government enterprises offer a 'physical safety net' to their female employees. They provide free shuttle bus services from home to work and return them immediately after regular working hours (this is also provided to male employees). The government also strictly observes Islamic dress codes and closely monitors gender relationships at work. The young women are generally uncomfortable with the level of close supervision. However, their protective parents appreciate government policies of enforcing a strict division between men and women employees, keeping the women at a 'healthy distance' from men. It has been a formidable challenge for Iranian women to resist parental pressure and seek employment in private organizations that offer freedom of movement and liberated space for productive work.

\subsubsection{The Challenge of Meeting Government Regulations Regarding the Dress Code}

The Islamic Republic has introduced and vigilantly enforced a female dress code, and a code of conduct which makes it rather difficult to associate with male colleagues at work. Women must wear the Islamic veil (hijab) and refrain from shaking hands with men. They are forbidden from cafeteria dining with their male coworkers. The externally imposed norms and values have made it difficult for the male managers to employ women as associates since their physical presence would place pressure on management to enforce a restrictive code of conduct. 
Phase 3 Conclusion: Employers generally maintain that the young men have flexible working schedules and are more influential with their customers in corporate positioning strategies. Men are perceived to be more effective on direct sales than women. Many female graduates of marketing programs ferociously dispute such perceptions and claim that they would be as effective as their male counterparts if provided equal opportunities. Afary (2009) maintains that the Iranian women have been perceived and treated as a secondary citizen throughout history. From interviews with a sample of Iranian women, Rezai-Rashti and Moghadam (2011) conclude that in contemporary Iran, women with higher education face gender discrimination in an unfavorable economic system that is not supportive to female employment.

\subsubsection{Phase 4: The Challenge of Succeeding in a Male-Dominated Domain}

The following observations were made pertaining to advancement in career opportunities for marketers:

\subsubsection{The Challenge of Operating in a Narrowly Defined Marketing Domain}

The recent inflow of foreign goods to the Iranian markets, blessed by high prices for the export of crude oil and petrochemicals, has broken a safety net that local manufacturers have long maintained through tariff protection and non-tariff barrier (NTB) policies of the Iranian government. For the local manufacturers to compete effectively with low cost imports from South Asia, they need to mobilize a comprehensive mix of marketing resources and strategies. This is particularly significant because, as Ranjbarian et al. (2011) have noted, there is a bias toward the better quality of imported merchandise, requiring a high level of marketing effort to overcome the unfavorable product position of domestic goods in consumers' minds. In this context, domestic marketers need to have a wide variety of marketing skills which would cover at least 33 different functions of marketing. Such a desirable quality of human resources rarely exists. Corporate managers, particularly those in state-owned enterprises, often hold a traditional view of marketing that is confined to promotion and sales. Many female marketers have reported to the author their frustrations in convincing their bosses to allocate resources to consumer profiling, product development, customer service, and logistics. They shared their feelings that the ideas of their male counterparts were more respected in their organizational challenge than the women comments and suggestions. At times the frustration was so severe that the female marketer had to quit her job. In a similar study, Lashgarara et al. (2012) concluded that marketing education is essential for the agricultural extension in marketing of pistachios in Iran.

\subsubsection{The Challenge of Expanding the Scope of Operations to Cover Marketing Strategy Formulation}

The organizational culture does not value women's potential to be meritorious for strategy formulation. They are perceived to be qualified only for implementing strategies adopted by the male executives. Tactical decisions by female employees are welcome, but opportunities for elevating to a higher decision making level has been suppressed by the organizational culture and hidden rules.

\subsubsection{The Challenge of Not Intruding the Male Manager's Comfort Zone}

It is not uncommon for many middle-aged and older executives to bring their cultural and social norms into the workplace, even if they are formally incompatible with the organizational mandate. Iranian men feel uncomfortable being around their female colleagues at work, as they will not be able to act as they would in an exclusively male environment. Many women felt that they had intruded into their manager's comfort zone when they asked for participation in the group decision-making. This situation has constrained the women's opportunities for designing marketing strategies in the male-dominated organizations.

\subsubsection{The Challenge of Breaking the Glass Ceiling for Advancement to Top Management}

Ghorbani and Tung (2007) apply the concept of "glass ceiling" to demonstrate situations where gender biases have restricted women from advancement within the Iranian organizations. The term "Glass Ceiling" was first used by two women at Hewlett-Packard in 1979, Katherine Lawrence and Marianne Schreiber, to describe how while on the surface there seemed to be a clear path of promotion, in actuality women seemed to hit a point which they seemed unable to progress beyond (Taneja, Pryor, Humphreys, 2009). Observations from other scenarios involving former students of the present author revealed that female marketers can be promoted to the position of marketing manager but possess limited authority to formulate marketing strategies. They could hardly be promoted to the rank of senior executive in state-run corporations, which control over $80 \%$ of the total assets of the Iranian economic enterprises. The few women managers who have advanced to top management positions have often resorted to highly complicated diplomatic tactics to secure the consent of top management. 


\subsubsection{The Challenge of Persuading Male Managers to Engage in Business Relations}

An array of societal impediments to healthy and productive business relationships has frustrated women's strife to market corporate offerings to a number of male purchasing agents. The prevalence of organizational culture that views business functions as fundamentally a male oriented trait, particularly in the area of marketing management where daily contacts need to be made with traders in the traditional markets (bazaar), shields access to lucrative marketing opportunities.

\subsubsection{The Challenge of Balancing the Work Expectations with the Household Chores}

For married women, especially those with a demanding home life, the conflict between the increasingly high requirement of the workplace, and the increasingly higher expectation of spouse and children, has created high level of stress. Ultimately those women who have strong job loyalty had to settle for family separation. Women who gave priorities to family life returned to their non-managerial responsibilities or quit the corporation entirely. From their study of 400 women and 172 men who applied to the divorce and marriage office of Quazvin Province in Iran during three months in 2009, Barikani, Ebrahim, and Navid, (2012) concluded that "dependency to families" was among the four significant factors for seeking divorce.

Phase 4 Conclusion: For those female marketers who have successfully overcame a gridlock of impediments to access university education, coping with restrictive environments in their semi-segregated learning space, convincing recruiters of their great abilities and potentials for the job, and finally entering the male-dominated organization, it has been frustrating to confront further restrictions on their career achievements and personal growth. Many young and educated Iranian women could not break the glass ceiling of the organizations to be promoted to executive positions.

\subsubsection{Phase 5: The Challenge of Overcoming a Restrictive Working Environment}

The following observations were made;

1) The large and formal organizations of women are associated with Islamic ideology and maintain close relationships with the state authorities. They have made moderate attempts to use their voice in the government for improvement of women conditions, with apparently limited success.

2) Iranian women have been traditionally underrepresented in the Parliament. Currently only $3.1 \%$ of the legislatures are women. They have regularly called for the enhancement of women's rights but often been frustrated due to their extremely low representation. In 2003 they were able to secure the support of their male colleagues and sign a petition by 156 members of the parliament (from a total of 290) that requested the President of the Islamic Republic to stop the implementation of a gender equalization strategy which would have prevented many qualified women from entering public universities.

3) Informal groups of educated Iranian women have expressed their voice and demanded fewer restrictions on women participation in business, government, and social organizations. They are beginning to see positive results. As Shirazi (2012) observes, the Iranian women have used the Internet, mostly via blogs, to voice their concerns and demands for equal treatment and equal pay.

4) A number of social scientists and women rights activists have offered strategies for overcoming the restrictive environment to those women who participate in executive positions of industry and commerce.

5) Dehghan (2012) argues that private universities have been able to provide additional opportunities when the scarcity of public funds falls short of serving all qualified applicants. Although the cost to the students is relatively high, the resources used by private universities are about one-fifth of those utilized by state-owned institutions. By shifting public resources to private educational institutions and providing subsidies, a greater number of qualified students (including women) will benefit in the process.

6) Women in the rural areas have exhibited an increasing level of empowerment in making decisions on household budgets. Likewise, they have gained legal knowledge to enhance their positions within the family and in the community as a whole (Soroushmehr et al, 2012). This has been partiality the results of attending high schools and utilizing the Internet frequently.

\section{Implications}

\subsection{For Global Corporations Who Enter Iranian Markets and Need Dynamic Marketing Managers for Success}

1) In spite of a high rise in the price of crude oil and its subsequent impact on the revenues of the Iranian government, a good portion of increased revenues has been channeled toward security and military operations, leaving little for social projects (Farzanegan, 2011). This implies that the expansion of consumer markets in the 
Islamic Republic requires new challenges which could be posed best by well-trained and deeply committed executives. The new breed of Iranian female marketers have demonstrated these qualities.

2) The landscape of job market for professional marketing positions is now populated with more university trained women than men. This has been a far cry from just a few years ago where men dominated the entire marketing activities, leaving women in secretarial and low level administrative positions.

3) The young female marketers are well educated; less experienced than their male counterparts, but are eager and prepared to work hard.

4) The young Iranian female marketers have invested more in learning English than their male counterparts, but may still have difficulties to communicate fluently. Nonetheless, they are willing to learn.

5) Many Iranian women are willing to work long hours in the organizations if they find the place safe and approved by their parents or husband. Subsidiaries of international corporations are usually perceived to be safe and secure places to work.

6) Many Iranian women perceive their local business to discriminate against them. They prefer working for foreign corporations as they consider them to be rational and fair.

\subsection{For the Iranian Government Officials Who Support the Training of Marketing Managers}

1) There has been an increasing demand by the female university graduates to have more freedom on the job than the government has provided them. Bureaucratic resistance to such demands has been faltering. None the less, there are still many restrictions which keep Iranian women frustrated with their work in government organizations.

2) Although Iranian women are not organized to appear as a formidable challenge to government restrictions, the wide use of the Internet has brought them together into a united front to gain more freedom at work and social interaction.

3) There is an apparent paradox in the perception of government constraints on women conduct within state-owned enterprises. While the young female employees perceive the constraints to be limiting, their parents and husbands find them to be a virtue for women employment. They believe state constraints on the freedom of movement would make the government buildings a safe and healthy environment for female employees to work. Parental pressure encourages women to work for government corporations which providelower working hours, more vacation time, job stability, and liberal policies for temporary leaves. Salaries, however, are significantly lower than in private firms.

\subsection{For the Iranian Communities Which Interact with Women Marketers}

1) There is an apparent display of frustration, and at times anger, by Iranian women who have not seen the benefits of their long academic education yielded the freedom of movement in the society or access to rewarding careers.

2) Many Iranian women who are frustrated with their living conditions (not so much materially than spiritually) have been seeking temporary residence in western societies. A conventional approach to this end has been admission to a foreign university with the intention of remaining there after graduation.

3) Many Iranian parents believe that their communities have become more risky for their daughters to live and work. They exert more limitations on unmarried daughters to limit their social life to immediate relatives and staying at home during evening hours.

4) Warm marketing has not been successfully practiced in the Iranian markets because it is against the cultural traits of the Iranians to sell consumer goods to their friends and relatives. Collecting money in a transaction does not merit positive values. In spite of the fact that recent economic difficulties have weakened these norms and beliefs, many Iranian women still shy from selling merchandise to relatives and friends.

5) Many female university graduates aspire to a lifestyle that enables them to have a socially respectable and economically rewarding career, which allows them to remain single until they are prepared for marriage. The Iranian society still frowns upon such a lifestyle. Many property owners are not willing to rent dwelling units to single women, even when a group of them apply for shared living in a residence. Lutz et al (2010) concluded that over the past two decades the country of Iran has experienced the world's most rapid fertility decline among 120 countries which were selected for their comparative study. Such decline was associated with massive increases in female education. 
6) The female perception of male behavior at work and in society is marred with a profound suspicion of possible inappropriate relationships even though they may be purely professional and work-related. These suspicions, reaffirmed by their parents and mentors, have made it very difficult for the young Iranian women to work with men in corporate committees. Many employers are aware of these suspicions and intentionally limit the work relationship that could have otherwise been fruitful and productive to their enterprise.

\section{Acknowledgements}

The author acknowledges with thanks constructive comments from his colleagues, Professors Earl Benson and T.J. Olney, on earlier drafts of this paper.

Financing for this research was provided through a summer research grant and a sabbatical leave from the College of Business and Economics, Western Washington University.

\section{References}

Afary, J. (2009). Sexual Politics in Modern Iran. Cambridge, UK: Cambridge University Press.

Afshari, R. (2012). Iran: An Anthropologist Engaging the Human Rights Discourse and Practice. Human Rights Quarterly, 34(2), 507-545. http://dx.doi.org/10.1353/hrq.2012.0039

Amouzesh. (2008). Gender-based Rationing for Entrance Examinations Became Official.

Bahramitash, R., \& Kazemipour, S. (2006). Myths and Realities of the Impact of Islam on Women: Changing Marital Status in Iran. Critical Middle Eastern Studies, 15(2), 111-128. http://dx.doi.org/10.1080/10669920600762066

Bahramitash, R., \& Salehi, E. H. (2011). Veiled Employment: Islamism and the Political Economy of Women's Employment in Iran. Syracuse: Syracuse University Press.

Barari, M. (2011). Ethnocentrism among Iranian Consumer with Different Consumption Habits. International Journal of Marketing Studies, 3(3), 1-13. http://dx.doi.org/10.5539/ijms.v3n3p30

Barikani, A., Ebrahim, S. M., \& Navid, M. (2012). The cause of divorce among men and women referred to marriage and legal office in Qazvin, Iran. Global Journal of Health Science, 4(5), 184-191. http://dx.doi.org/10.5539/gjhs.v4n5p184

Beck, L., \& Guity, N. (2004). Women in Iran from 1800 to the Islamic Republic. Urbana: The University of Illinois Press.

DanaeeFard, H., \& Noruzi, M. R. (2010). Some Issues for Women in Cooperative Sector in Iran. Interdisciplinary Journal of Contemporary Research In Business, 2(7), 408-411.

Ezzati, A. (2008). The Perils of Entrance Examinations. Retrieved from http://www.konkorbartar.com/news.php?extend. 522.23

Fararou. (2008). The Bewildered Educated Girls in the Society. Retrieved from http://www.fararu.com/vdci5raz.t1av52bcct.html

Ghorbani, M., \& Tung, R. L. (2007). Behind the Veil: An Explanatory Study of the Myths and Realities of Women in the Iranian Workforce. Human Resource Management Journal, 17(4), 376. http://dx.doi.org/10.1111/j.1748-8583.2007.00051.x

Hoffman, E. P. (2012). A Review of Veiled employment: Islamism and the political economy of women's employment in Iran. Current Reviews of Academic Libraries, 49(6), 1115-1116.

Hoodfar, H., \& Sadeghi, F. (2009). Against All Odds: The Women's Movement in the Islamic Republic of Iran. Development, 52(2), 215-223. http://dx.doi.org/10.1057/dev.2009.19

Hoodfar, H., \& Sadr, S. (2010). Islamic Politics and Women's Quest for Gender Equality in Iran. Third World Quarterly, 31(6), 885-903. http://dx.doi.org/10.1080/01436597.2010.502717

Jahanshahrad, H. (2012). A Genuine Civil Society and its Implications for the Iranian Women's Movement. Women's History Review, 21(2), 233-252. http://dx.doi.org/10.1080/09612025.2012.657883

Kar, M., \& Farshi, G. (2008). Focusing on Women in the Internal Politics of Iran. Brown Journal of World Affairs, 15(1).

Kerman, S. F., Navidian, A., NavabiRigi, S., \& Montazeri, A. (2012). Comparing health-related quality of life of employed women and housewives: a cross sectional study from Southeast Iran. BMC Women's Health, 12(1), 41-45. http://dx.doi.org/10.1186/1472-6874-12-41 
Keshavarz, F. (2008). Rethinking Global Sisterhood: Western Feminism and Iran. Middle East Journal, 62(2), $340-41$.

Keshavarzian, A. (2009). Regime Loyalty and Bāzārī Representation Under The Islamic Republic of Iran: Dilemmas of The Society of Islamic Coalition. International Journal of Middle East Studies, 41(2), 225-246. http://dx.doi.org/10.1017/S0020743809090643

Khosrokhavar, F., \& Ghaneirad, M. (2010). Iranian Women's Participation in the Academic World. Iranian Studies, 43(2), 223-238. http://dx.doi.org/10.1080/00210860903542093

Lashgarara, F. (2012). Implications and Challenges of Agricultural Extension in Marketing of Pistachios. ARPN Journal of Agricultural and Biological Sciences, 7(1), 1-7.

Lutz, W., Cuaresma, J., \&Abbasi-Shavazi, M. (2010). Demography, Education, and Democracy: Global Trends and the Case of Iran. Population \& Development Review, 36(2), 253-281. http://dx.doi.org/10.1111/j.1728-4457.2010.00329.x

Maftei, C. (2010). The Sanctions of the Islamic Criminal Law: Aspects Regarding Penalties of the Criminal Law of the Islamic Republic of Iran. Religion and Tradition vs. Observing Human Rights. Juridical Current, 13(3), 139-148.

Mehran, G. (2009). Doing and Undoing Gender: Female Higher Education in the Islamic Republic Of Iran. International Review of Education / InternationaleZeitschriftü̈rErziehungswissenschaft, 55(5/6), 541-559. http://dx.doi.org/10.1007/s11159-009-9145-0

Moghadam, S., Knudson-Martin, C., \& Mahoney, A. R. (2009). Gendered Power in Cultural Contexts: Part III. Couple Relationships in Iran. Family Process, 48(1), 41-54. http://dx.doi.org/10.1111/j.1545-5300.2009.01266.x

Neyestani, M. D. (2012). The Role of Private Higher Education in Providing Professional Human Resources and Financial Resource in Iran. International Journal of Business and Social Science, 3(7), 198-202.

Nikkhah, H., Redzuan, M., \& Abu-Samah, A. (2012). Development of 'Power within' Among the Women: A Road to Empowerment. Asian Social Science, 8(1), 39-46.

Official State Gazette. (2013). The Act of Iranian Parliament to Extend Maternity Leave to Nine Months, Tehran, Iran (February 20, 2013).

Osanloo, A. (2009). The Politics of Women's Rights in Iran. Princeton: Princeton University Press.

Ranjipour, A. (2008). Admission Localization Following Gender Rationing. Etemad (Farsi) No. 1787 (15 Mehr 1387).

Rezaee, R., Soofi, A., \& Lotfi, F. (2012). Gender and Education; Progress and Challenges in Girls' Education in Iran. European Journal of Social Sciences, 27(2-4), 400-407.

Rezai-Rashti, G., \& Moghadam, V. (2011). Women and Higher Education in Iran: What are the Implications for Employment and The 'Marriage Market'? International Review of Education, 57(3/4), 419-441. http://dx.doi.org/10.1007/s11159-011-9217-9

Safavi, F. (2009). Challenges of Women Marketing Managers in an Islamic Republic: Reflections from a Summer Teaching at Tehran University. Proceedings of the American Society of Business and Behavioral Sciences, $16^{\text {th }}$ Annual Conference, Las Vegas, Nevada: February 18-21.

Safavi, F. (2012). Revisiting the Challenges of the Women Marketing Managers in the Islamic Republic of Iran: A Field Study of Women Struggle in a Male Dominated Environment. Proceedings of the International Academy of Business and Public Administration Disciplines, Dallas, Texas: April 19-20, 2012.

Sakurai, K. (2012). Shi'ite Women's Seminaries (howzeh-ye 'elmiyyeh-ye khahran) in Iran: Possibilities and Limitations. Iranian Studies, 45(6), 727-744. http://dx.doi.org/10.1080/00210862.2012.726846

Shirazi, F. (2012). Information and Communication Technology and Women Empowerment in Iran. Telematics and Informatics, 29(1), 45-55. http://dx.doi.org/10.1016/j.tele.2011.02.001

Soroushmehr, H., Kalantari, K., ShabanaliFami, H., \& Sarani, V. (2012). Investigation of Self-help Groups (SHGs) Effect on Rural Women Empowerment (Hamedan Country, Iran). Journal of Agricultural Science, 4(1), 1-11. 
Tahmasebi-Birgani, V. (2010). Green Women of Iran: The Role of Women's Movement During and After Iran's Presidential Election of 2009. Constellations: An International Journal of Critical and Democratic Theory, 17(1), 78-86. http://dx.doi.org/10.1111/j.1467-8675.2009.00576.x

Taneja, S., Pryor, M. G., \& Humphreys, J. (2009). Empowerment from the Gender Perspective. Delhi Business Review, 10(2).

Terman, R. (2010). The Revolutionary Muslim Woman in the Islamic Republic of Iran: The Piety of Public Participation. Totalitarian Movements \& Political Religions, 11(3/4), $289-310$. http://dx.doi.org/10.1080/14690764.2010.546086

\section{Note}

Note 1. The author noted a very interesting phenomenon in the Iranian's response behavior to face to face interviews. Whenever questions were posed with no recording of the data and no taking of the notes with paper and pencil, the respondents appeared to be in a comfortable mode as they expressed their unfiltered feelings toward the topic. As soon as the author opened his briefcase and started jotting notes, the respondents appeared to be uncomfortable. The tone of responses was instantly altered to a matter of fact style using politically correct expressions of generally accepted opinions. It was on the basis of this Iranian specific pattern of revealing personal values and opinions that the author abandoned the traditional method of posing structured questions. He applied an alternative which placed the respondent in a comfortable position with opportunities to express whatever comes to mind. 